\title{
Assessing population changes from disparate data sources: the decline of the Twite Carduelis flavirostris in England
}

\author{
ANDRÉ F. RAINE, ANDREW F. BROWN, TATSUYA AMANO \\ and WILLIAM J. SUTHERLAND
}

\section{Summary}

Conservationists often find it difficult to assess long-term population change in a species when the only data available are from disparate sources. This is especially the case when a range of survey methodologies and reporting units have been utilised and the results have been published in the 'grey' literature. Although the production of a cohesive assessment of change may be a daunting task, in such circumstances, a sound assessment of change is often possible. We illustrate this by considering the decline of the Twite Carduelis flavirostris in England. Whilst there is evidence of decline, it is widely dispersed and the losses have yet to be formally documented. To assess longer-term change, we reviewed information available in county avifaunas and historical accounts of the status of the species throughout its former English range. Twite now only breed regularly in six of their 12 historical range counties, and in all of these six, the birds have declined markedly in abundance. We collated and analysed data drawn from a diverse range of surveys and county bird reports to assess more recent change and assessed contemporary distribution and abundance during our own surveys of breeding colonies in the South Pennines, an area supporting the last known nesting colonies in England. Combined, the data clearly indicate that the range and numbers of breeding Twite have declined considerably since the 1970s. Recent re-surveys in the South Pennines indicate a significant range contraction, with a loss of Twite from $83 \%$ of $1-\mathrm{km}$ grid squares found occupied during a 1990 survey. A detailed resurvey of historical breeding sites in east Lancashire revealed a similar pattern, with $77 \%$ of sites having lost their colonies over the last four decades. We also constructed an index of change in numbers on the east and south-east coastal wintering grounds used by English breeding birds and this shows that numbers have severely declined since the 1970s, mirroring change on the breeding grounds.

\section{Introduction}

A clear understanding of population change can be difficult to obtain when the relevant data are dispersed across a range of primary sources, especially when these differ widely in scientific rigour and style or format of presentation. This is often the case for species that, for whatever reason, are poorly represented in national monitoring schemes or are difficult to monitor in the field. In this paper we consider how to assimilate data from a range of sources to create a coherent picture of population change and provide an index of change. We illustrate this using data on the changing status of Twite Carduelis flavirostris in England.

A sustained period of decline in the range and size of many of Britain's farmland bird populations (Fuller et al. 1995, Siriwardena et al. 1998, Shrubb 2003, Newton 2004) has coincided with a marked period of agricultural change over the last 60 years (Robinson and 
Sutherland 2002, Shrubb 2003). The losses are well-documented (Marchant et al. 1990, Fuller et al. 1995, Siriwardena et al. 1998, Fewster et al. 2000) as these affected species have, for the most part, been well-represented in the long-term data collected by the BTO/JNCC Common Bird Census (Marchant 1983) and its successor, the BTO/JNCC/RSPB Breeding Bird Survey (Joys et al. 2003). Widespread concern about these losses has been a spur to a considerable body of research into the reasons underlying these trends (Aebischer et al. 2000, Chamberlain 2004). The UK government has also adopted a Farmland Bird Index as one of its 15 Quality of Life indicators (Anon 1999) and created a UK Public Service Agreement to reverse these declines by 2020 (Anon 2002, Vickery et al. 2004).

The populations of many species considered to be 'upland birds' also use farmland for much of the year - variously for nesting, foraging and roosting. As the uplands have not escaped agricultural intensification and other land use changes (Fuller and Gough 1999, Jenkins and Watson 2001, Shrubb 2003, Brown and Grice 2005), it is entirely possible that there have been parallel losses amongst upland species. However, the population trends of upland species are rather poorly documented (Fuller et al. 2002), largely because upland areas tend to be remote from centres of human population (and thus potential volunteers) and have therefore been poorly represented in volunteer-based long-term schemes. For example, the upland Pennines were represented by just two Common Bird Census plots that had been monitored for a period of ten years or more (Fuller et al. 2002). The evolution of the scheme into the Breeding Bird Survey (BBS) was, in part, in recognition of the need to improve representation in habitats other than woodland and lowland farmland (Baillie et al. 2005).

In England, Twite now breed exclusively in upland areas. While the species is listed as 'Least Concern' in the Global IUCN Red List (BirdLife International 2004), in England it is classified as a red-listed Species of Conservation Concern due to historic population declines and range contractions (Gregory et al. 2002). It is also a UK Government Biodiversity Action Plan priority species by virtue of its more recent decline. Twite are difficult to survey using non-specific methodologies as they are colonial and conduct most feeding, courtship and display activity well away from the nest site (Gilbert et al. 1998). There has been just one national census, leading to an estimate of the size of the British population of 10,000 pairs (Langston et al. 2006). The majority of birds are found in Scotland, where the birds are most numerous in north and northwestern coastal areas. There are an estimated 3,500 pairs in Ireland and a small population in Wales (Gibbons et al. 1993). In England, the main breeding population is located in the South Pennines, where the population is estimated at between 200 and 400 pairs (Brown et al. 1995, Batty et al. 1999). The only estimate of the British wintering population is of $100,000-150,000$ individuals (Lack 1986), these predominantly inhabiting coastal saltmarshes and occasionally arable farmland at or near the coast.

There is some good evidence that both the range and numbers of the species have diminished in recent decades (Brown et al. 1995, Batty et al. 1999, Langston et al. 2006), but much of the evidence for a decline is anecdotal, unpublished or uncollated. This paper attempts to formally document changes in the English Twite population using evidence drawn from unpublished surveys, county avifaunas and county bird reports, as well as our own data collected during fieldwork in the South Pennine Moors Site of Special Scientific Interest (SSSI). We also demonstrate that it is possible to produce a convincing quantitative assessment of population change, through the creation of an index, using data of variable quality drawn from disparate sources. We argue that it may be useful to adopt the approach more widely in assessing change in species or populations poorly represented in bespoke schemes.

\section{Methods}

In order to assess change in the distribution and abundance of Twite, we collated and analysed information extracted from county bird reports, county avifaunas and other historical accounts of the status of the species throughout its former range, many of which include reference to the 
bird's status back to the start of the nineteenth century. Due to the considerable variation in the way data are presented in the various sources, broad abundance categories were used to chart the change in the status of this species in each county (Table 1 ).

More recent changes in abundance and distribution (since 1990) were examined by comparing data collected during survey work covering the known breeding season of this species in the uplands of England (late April to end of July) in 2004 and 2005 with that obtained over the same period in 1990 for the same sites in the South Pennine Moors Special Protection Area (SPA) (which encompasses the South Pennines SSSI and three other SSSIs in the Peak District National Park) (Brown et al. 1995). The recent surveys used the same census methods as the originals and are thus directly comparable. Data were plotted onto maps using MapInfo Professional Version 4.1.2. (MapInfo Corporation 1997). We also examined change in Twite numbers in Staffordshire since 1927 using data from Harrison and Harrison (2005), with updates from Staffordshire Bird Reports. Fieldwork carried out by Raine (2006) between the breeding seasons of 2003 and 2005, which consisted of thorough breeding surveys of all suitable breeding habitat in the South Pennine Moors SSSI, was used to generate population estimates for the region.

In 1967 and 1968, detailed surveys of breeding Twite were conducted by the East Lancashire Ornithological Club (Nuttall 1968). We were able to accurately identify the locations of a significant number of the Twite colonies and Twite nests found during this survey using six-figure grid references (a means of describing locations on UK Ordnance Survey maps to the nearest $100 \mathrm{~m}$ ). We re-surveyed 43 sites with confirmed Twite colonies in 1967 or 1968 during the known breeding season of this species in either 2004 or 2005 . Breeding behaviour was taken to be that described by Gilbert et al. (1998) and was defined as: (i) flight displays over suitable nesting habitat, (ii) birds carrying nesting material into suitable nesting habitat, (iii) the presence of distinct pairs, (iv) the presence of recently fledged young, (v) agitated behaviour at a potential nest site, (vi) a bird reluctant to leave an area where flushed (often circling the surveyor and making alarm calls), or (vii) nests. Twite exhibiting any of these behaviours were assumed to be breeding in the area.

Twite breeding in the north of England, particularly in the South Pennine Moors SPA, spend the winter predominantly on the south and south-east coast of England (Brown and Atkinson 2002, Raine et al. 2006). We collated the information available concerning trends in the numbers of Twite at known key wintering sites in this area. We obtained information from county bird reports (using highest mid-winter counts between November and February), the Wetland Bird Survey (WeBS), bird observatories and our own extensive surveys conducted during the winters of 2003/04 to 2005/06. Twite are found elsewhere in England in winter, predominantly in northwestern coastal areas (Lack 1986), but as the majority of these are birds from breeding areas in western Scotland (Raine et al. 2006) we have not included them in our study. Neither have we included upland wintering flocks as, historically, the presence of Twite in such areas is rather erratic (Oakes 1953, Orford 1973).

There is considerable variation, both between years and between counties, and especially prior to the late 1990s, in the detail provided in county bird reports. Generally, reports give maximum

Table 1 . Description of abundance categories used to describe Twite breeding populations in range counties.

\begin{tabular}{lc}
\hline Abundance Category & Description \\
\hline Common & Reported as breeding in the majority of suitable \\
hrequent & habitat in the county, often in large numbers \\
& Reported as breeding in many parts of the county, but \\
& not occupying all suitable habitats and often not \\
numerous & Sparsely distributed in the county, breeding in small \\
Uncommon & numbers \\
Rare & Few recods of birds reported from their breeding \\
& grounds. Breeding often unconfirmed \\
\hline
\end{tabular}


counts, but in some cases only indicate presence or absence and zero counts are but rarely reported. We employed a modelling approach to construct a smoothed population trend from the time-series counts available for some wintering sites. We followed the methodology used by Fewster et al. (2000), in which population counts were modelled as the summation of a site factor and a smooth function of a year factor using a generalised additive model (GAM) with a log link and Poisson errors. The model was fitted to the data between the winters of $1964 / 65$ and 2005/06 from five sites in the county of Essex, nine in Lincolnshire, six in Norfolk, two in Cambridgeshire, one in Staffordshire and one in Suffolk. The model used maximum counts between November and February for each site. Following Fewster et al. (2000), the degree of freedom was set as 0.3 times the length of the time series ( 12 for 41 years of data) to fit the GAM and the year 2005 was set as a base year to derive the index measuring relative abundance in each year. Confidence intervals for the indices were estimated using bootstrapping (399 samples). The percentage changes in the estimated index, together with bootstrapped confidence intervals, were also calculated. Modelling was carried out using the code by Fewster et al. (2000) using the computer language $\mathrm{R}$ (R Development Core Team 2006).

\section{Results}

\section{Breeding Grounds}

Figure 1 illustrates the changing status of Twite as a breeding bird in each of its known historical breeding-range counties. Only six out of the 12 counties $(50 \%)$ retained Twite as a breeding species by 2005. The location of each of these counties is shown in Figure 2.

\section{COUNTY}

Northumberland

Durham

Yorkshire

Lancashire

Cheshire

Derbyshire

Nottinghamshire

Staffordshire

Warwickshire

Worcestershire

Herefordshire

Shropshire

Devon
Cumbria
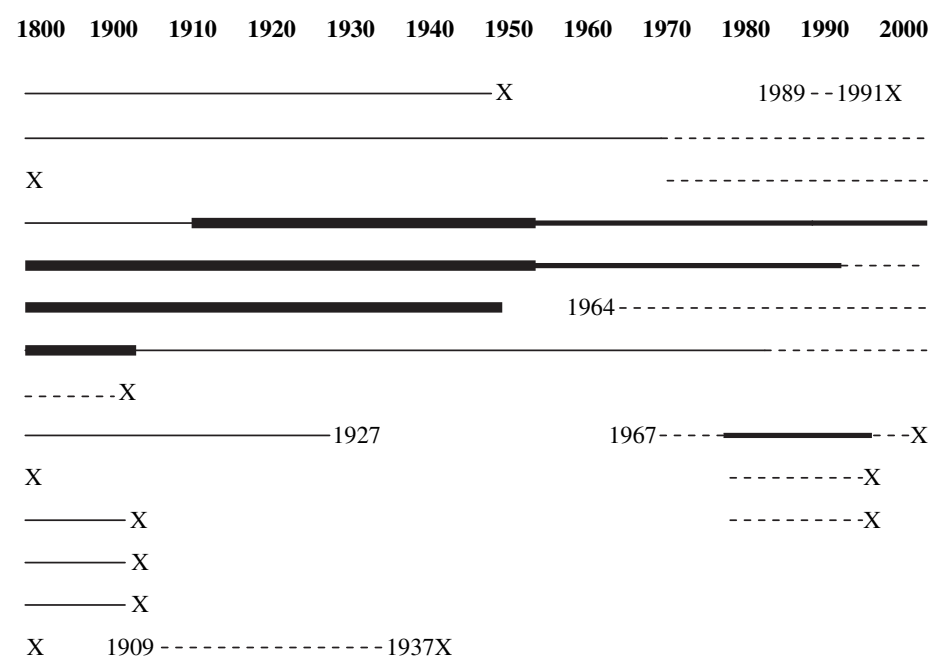

KEY :

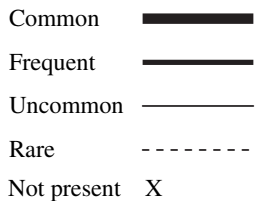

Figure 1. The changing status of breeding Twite in each of its English range counties. Dates represent first or last confirmed breeding record for a county, where known. 


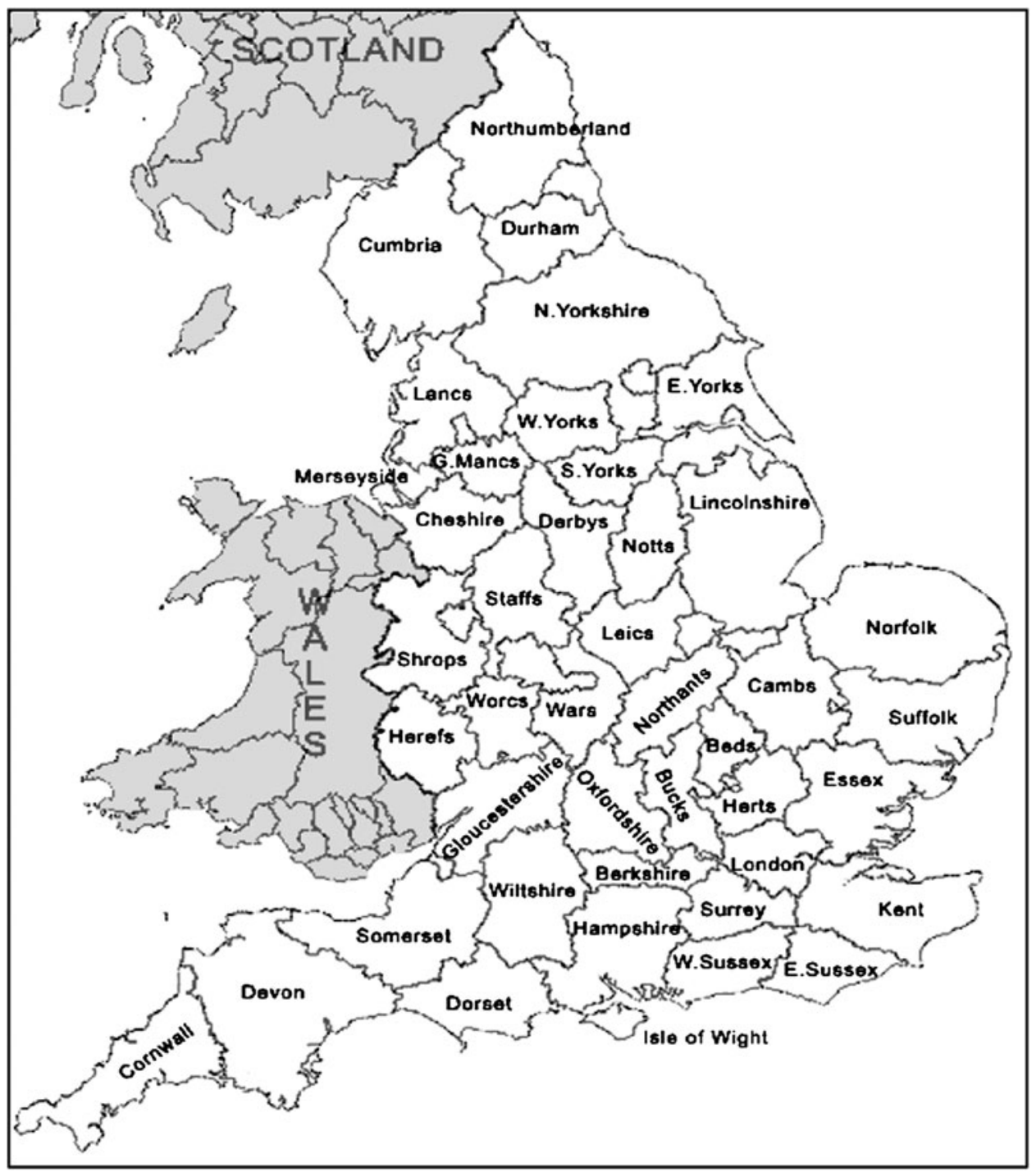

Figure 2. Map of England showing the location of counties.

The 2004 and 2005 resurveys of the South Pennine Moors SPA indicate dramatic losses since 1990 (Figure 3). The Peak District National Park occupies much of the southern half of this area, and here numbers fell from 131 pairs in 1990 to just 10 in 2004 with the number of $1-k m$ squares occupied by Twite in the breeding season declining from 88 in 1990 to only seven in 2004 (Carr and Middleton 2004). These changes represent a fall in both abundance and occupancy of $92.0 \%$. The same trend was evident in the South Pennines SSSI, which occupies much of the northern part of the SPA. Numbers here fell from 219 pairs in 1990 to 57 in 2004/05 (a decline of $74 \%$ ), with birds recorded in $1491-\mathrm{km}$ squares in 1990 and 37 in 2004/05, a decline of $77.2 \%$. Over the entire SPA, the number of 1 -km squares occupied by Twite fell from 280 in 1990 to 47 in 2004/5, representing an overall loss of $83.2 \%$. 

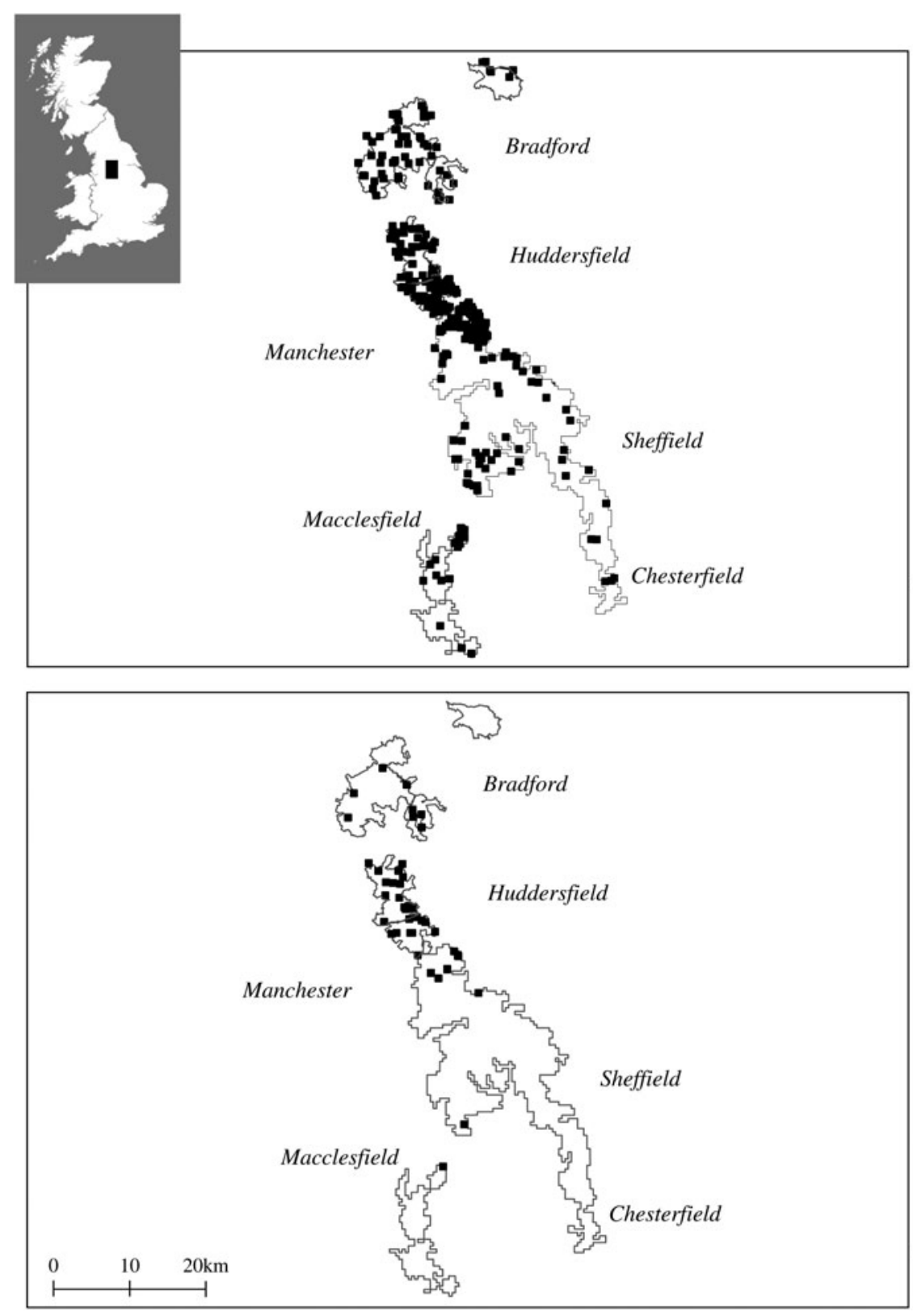

ii. $2004 / 05$

Figure 3. Maps showing distribution of Twite found during upland surveys in the South Pennine Moors SPA in i) 1990 and ii) 2004/05. Each square on the map represents a $1-k m$ grid square where breeding Twite (pairs or colonies not differentiated) were recorded.

Of the 43 colonies known to be occupied by breeding Twite in east Lancashire in 1967 and 1968 that we resurveyed in 2004 and 2005, Twite had apparently been lost from 33 (76.7\%) (Table 2). In some cases, colonies of substantial size (as large as 50 pairs) had disappeared in the intervening period. Data concerning year on year changes were available for three upland areas in northern 
Table 2. Comparison of maximum Twite colony size for historical breeding sites in Lancashire and West Yorkshire.

\begin{tabular}{|c|c|c|c|c|}
\hline No. & Site Name & Grid Reference & $\begin{array}{l}\text { Population Estimate } \\
1967 / 1968\end{array}$ & $2004 / 2005$ \\
\hline 1 & Boulsworth Hill & SD9236 & 50 & o \\
\hline 2 & Crown Point Moor & SD8429 & 25 & o \\
\hline 3 & Sutton Moor & SEoo41 & 18 & o \\
\hline 4 & Nutshaw Hill & SD8228 & 12 & o \\
\hline 5 & Green Haworth Moor & $\mathrm{SD} 7626$ & 11 & o \\
\hline 6 & Crawshawbooth & SD8125 & 10 & o \\
\hline 7 & Deerplay Moor & SD8626 & 10 & o \\
\hline 8 & Gorple Moor & SD9231 & 10 & o \\
\hline 9 & Deerstone Moor & SD9036 & 9 & o \\
\hline 10 & Darwen Moor & SD6819 & 8 & o \\
\hline 11 & Haslingden Moor & $\mathrm{SD}_{7523}$ & 8 & o \\
\hline 12 & Ogden Res & $\mathrm{SD} 7623$ & 8 & o \\
\hline 13 & Withnell Moor (Site I) & SD6419 & 7 & o \\
\hline 14 & Delf Hill & SD8933 & 6 & o \\
\hline 15 & Stipperden Moor & SD9128 & 6 & o \\
\hline 16 & The Hile (Site I) & $\mathrm{SD} 8523$ & 6 & o \\
\hline 17 & Darwen Moor Quarry & SD6821 & 5 & o \\
\hline 18 & The Hill (Site 2) & SD8522 & 5 & o \\
\hline 19 & Cowpe Lowe & SD8220 & 4 & o \\
\hline 20 & Seat Naze/Scout Moor & SD8323 & 4 & o \\
\hline 21 & Swinden Reservoir & SD8932 & 4 & o \\
\hline 22 & Carr Head & SD8122 & 3 & o \\
\hline 23 & Smallshaw Heights & SD8524 & 3 & o \\
\hline 24 & Birchen Holts & SD8417 & 2 & o \\
\hline 25 & Dearden Moor & SD8120 & 2 & o \\
\hline 26 & Hall Carr & SD8121 & 2 & o \\
\hline 27 & Scout Moor & SD8219 & 2 & o \\
\hline 28 & Townsend Fold & SD8021 & 2 & o \\
\hline 29 & White Hill & SD6720 & 2 & o \\
\hline 30 & Will Moor Clough & $\mathrm{SD}_{9136}$ & 2 & o \\
\hline 31 & Withnell Moor (Site 2) & SD6420 & colony & o \\
\hline 32 & Deanhead & SEo314 & colony & o \\
\hline 33 & Duckshaw Clough & SD6820 & colony & o \\
\hline 34 & Buckstones & SEO212 & 12 & 15 \\
\hline 35 & Stansfield Moor & SD9328 & 10 & 3 \\
\hline 36 & Cant Clough & SD8931 & 5 & 25 \\
\hline 37 & Turvin Clough & SD9820 & colony & 15 \\
\hline 38 & Meltham & SEo81o & colony & 11 \\
\hline 39 & Fly Flatts & SEo331 & colony & 8 \\
\hline 40 & Withens Clough & SD9822 & colony & 6 \\
\hline 41 & Rishworth : Green Withens & SD9916 & colony & 6 \\
\hline 42 & RishWorth : Hell Bank & SEOI16 & colony & 6 \\
\hline 43 & Widdop Moor & SD9233 & colony & 2 \\
\hline
\end{tabular}

England: the Staffordshire uplands (Figure 4) and two upland Common Bird Census plots in the South Pennine Moors SSSI (Figure 5). These also show a marked decline in Twite numbers, with, additionally, their eventual loss. This is not the first time that the species has been lost from Staffordshire. After more than thirty years of absence, the area was re-colonised in 1967 and numbers increased rapidly to the mid-1980s before declining again to extinction. 


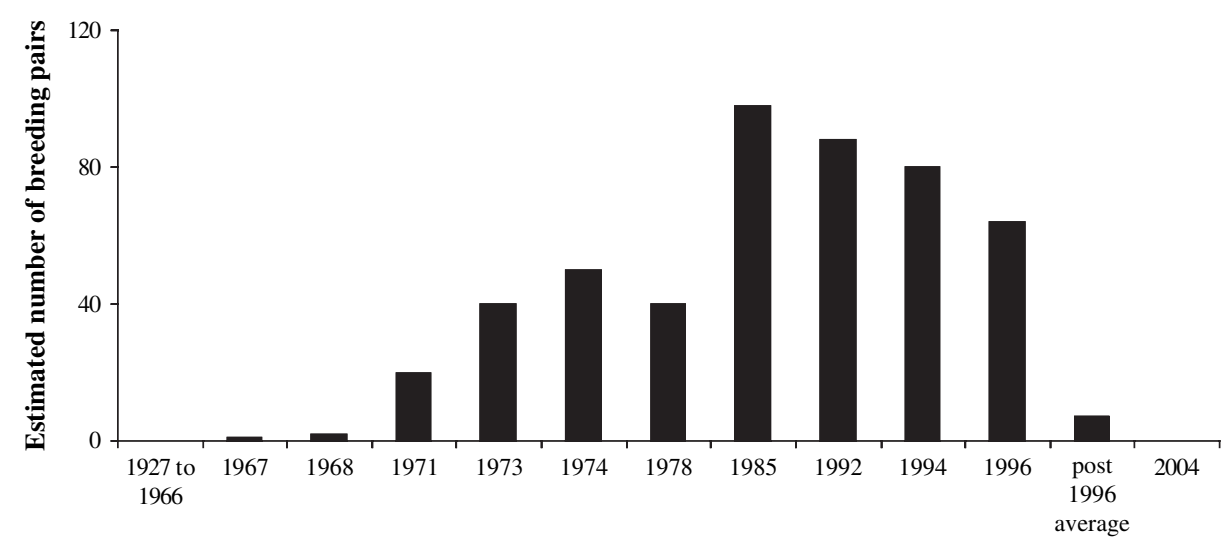

Year

Figure 4. Numbers of breeding Twite in Staffordshire, following recolonisation in 1967. Data from Harrison and Harrison (2005) and English Nature South Pennine Moors SPA resurvey (2004/05).

Obtaining an accurate estimate of the size of the South Pennines SPA Twite population is made difficult by the distribution of colonies across a large area of land. Nevertheless, we are confident that we know the location of practically all extant colonies in this area (using a combination of historical records, recent bird sightings and information from local birdwatchers throughout the South Pennines area) and so we have attempted to estimate the size of the total population by summing the lowest and highest number of breeding pairs recorded at each site over the three year study period (Table 3) to derive a minimum and maximum total of, respectively, 126 and 203 pairs. As this estimate incorporates extensive fieldwork conducted between 2003 and 2005 that encompassed all suitable breeding habitat in the entire region, it is probable that the true breeding

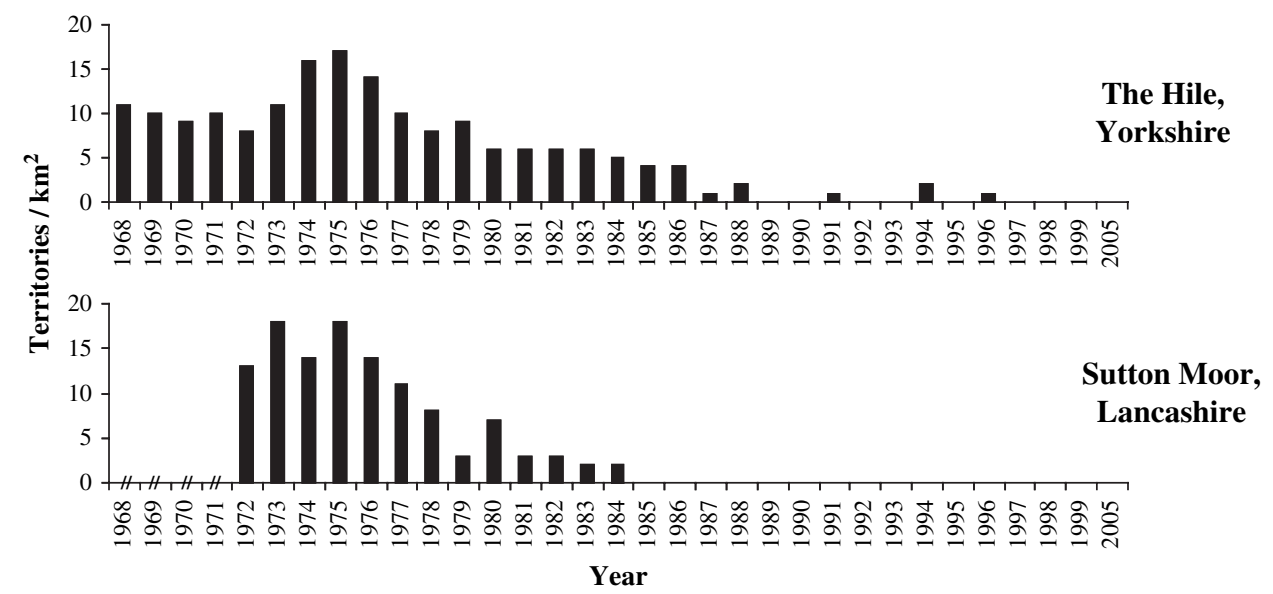

Figure 5. Estimated number of territories $\mathrm{km}^{-2}$ of Twite on two Common Bird Census plots in the English uplands. '//' symbols represent years where no data is available. Data collection on Sutton Moor started in 1972 and both sites were surveyed until 1999. We revisited both sites in 2005 . 
Table 3. Lowest and highest population estimates for the South Pennine Moors SPA, calculated by summing the known number of breeding pairs of Twite in all recorded colonies. For site estimates from this study, lowest and highest number of breeding pairs over the three year study period are given. For remaining estimates, which have been acquired from single surveys, the same number of breeding pairs is used in each column.

\begin{tabular}{|c|c|c|c|c|}
\hline No & Site Name & Estimate By & $\begin{array}{l}\text { Lowest \# of } \\
\text { breeding pairs }\end{array}$ & $\begin{array}{l}\text { Highest \# of } \\
\text { breeding pairs }\end{array}$ \\
\hline 1 & Lumbutts & This study & 25 & 50 \\
\hline 2 & Cant Clough & This study & 15 & 25 \\
\hline 3 & Rishworth (colonies grouped) & This study & 20 & 23 \\
\hline 4 & Turvin Clough & This study & 5 & 15 \\
\hline 5 & Buckstones & This study & 6 & 15 \\
\hline 6 & Meltham & This study & 2 & 11 \\
\hline 7 & Fly Flatts & This study & 5 & 8 \\
\hline 8 & Wessenden Moor & This study & 5 & 7 \\
\hline 9 & Withens Clough & This study & 2 & 6 \\
\hline 10 & Midgley Moor & This study & 5 & 6 \\
\hline 11 & Eldon Hill Quarry & This study & 6 & 6 \\
\hline 12 & Cupwith Moor & This study & 5 & 6 \\
\hline 13 & Bee Low Quarry & This study & 5 & 5 \\
\hline 14 & Stansfield Moor & This study & 3 & 3 \\
\hline 15 & Widdop Moor & This study & 2 & 2 \\
\hline 16 & Bleakedate Moor & South Pennine Moors SSSI survey & 2 & 2 \\
\hline 17 & Dean Moor & South Pennine Moors SSSI survey & 1 & 1 \\
\hline 18 & Haworth Moor & South Pennine Moors SSSI survey & 1 & 1 \\
\hline \multirow[t]{3}{*}{19} & Dove Stones & South Pennine Moors SSSI survey & 1 & 1 \\
\hline & Peak District National Park & Carr \& Middleton 2005 & 10 & 10 \\
\hline & & Total Breeding Pairs & 126 & 203 \\
\hline
\end{tabular}

population of Twite in the area lies somewhere in between these two figures. This also demonstrates the fluctuations in population size that individual colonies experience on a yearly basis.

\section{Wintering grounds}

For many decades, Twite have been reported from a number of coastal areas in eastern and southeastern England, and at a smaller number of inland sites. However, they are now scarce in or absent from many of these areas. Whilst the losses are particularly evident at sites in coastal East Anglia, our assessment of the changes in the numbers recorded at coastal sites in east, south and south-east England indicates that the decline has been more widespread. Our index reveals that the wintering population first increased in the 1960s, but declined extremely rapidly after the mid 1970s (Figure 6). The declines between 1965 and the 2005/2006 winter, 1975 and the 2005/2006 winter and 1985 the 2005/2006 winter were all significant (Table 4). But when the percentage change in the index was calculated for every decade, a significant downward change was only detected between 1985 and 1995 (Table 4), indicating that the decline in this period was particularly severe. We found similar patterns of change in Twite counts from Landguard Bird Observatory in Suffolk and from Gibraltar Point Bird Observatory in Lincolnshire, both migration watch points where birds are enumerated regularly (Figure 7).

Twite have long been known to visit some inland sites in winter, although they are more usually scarce or irregular visitors to such areas. Nevertheless, they have occurred in some numbers at a few sites, notably in East Anglia and counties near their breeding grounds. Figure 8 shows data from two such inland wintering sites (there may have been other small historical inland wintering sites, but these two sites were by far the largest and were the best documented 


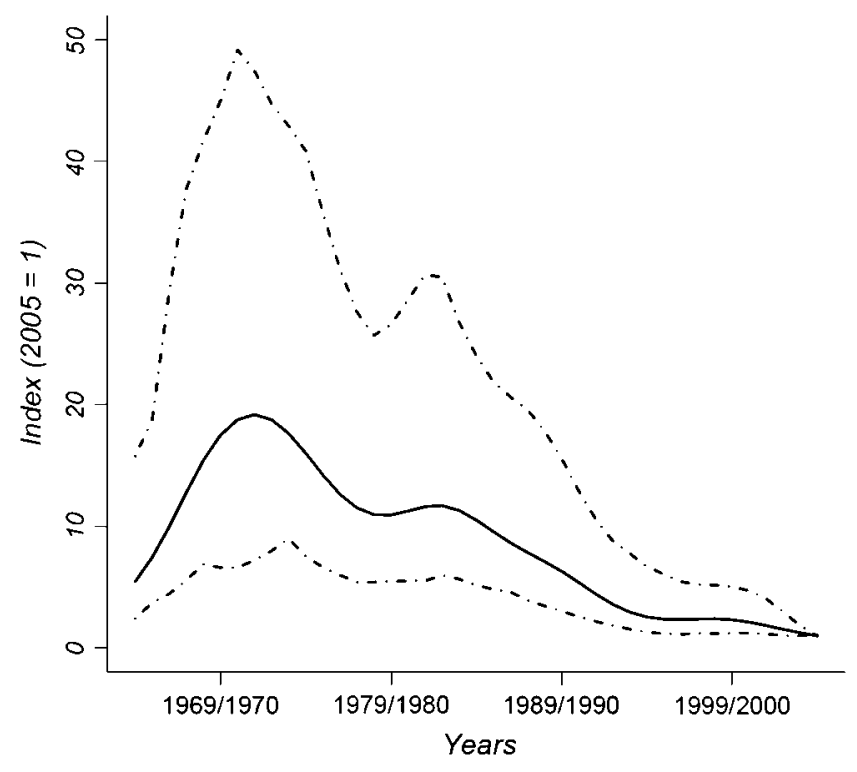

Figure 6. Index curve from maximum flock sizes in winter (November-February) for 24 traditional wintering sites on the south and south-east coasts of England. The solid line gives the index curve from a GAM with $12 \mathrm{df}$, and the dashed lines represent upper and lower $85 \%$ bootstrapped confidence limits. Source: WeBS counts (courtesy of David Bingham); County Bird Reports; Brown \& Grice, 2005.

with the most consistent datasets available). The Ouse Washes (National Grid Reference TL4685) in Cambridgeshire was once used regularly by Twite in winter, but no birds have been recorded here since 1995. In fact, only six Twite have been recorded in the whole of Cambridgeshire since 1999. By contrast, a flock of 300 individuals was present on the Ouse Washes during the winter of 1976/77. A similar trend is evident at Chasewater (National Grid Reference SKo307), an inland reservoir in Staffordshire. This site, once set in lowland heath, underwent habitat reclamation work (starting in 1974) and is now industrial land. Whether the loss of Twite at this site is related to land-use change or is merely a part of the birds' wider decline is not known. It is possible that the initial peak in numbers following the start of reclamation may have been due to an increase in the occurrence of seeding weeds on the now heavily disturbed site. Twite are known to feed

Table 4. Estimated percentage population changes, together with bootstrapped $95 \%$ confidence limits, for wintering Twites using output from a GAM with $12 \mathrm{df}$ fitted to maximum flock sizes in winter (NovemberFebruary) for 24 traditional wintering sites on the south and south-east coasts of England. The percentage change was obtained as $100\left(I_{2}-I_{1}\right) / I_{1}$, where $I_{1}$ is the index for the earlier year and $I_{2}$ is that for the later year. Changes that were significant at the $5 \%$ level are in bold.

\begin{tabular}{lll}
\hline & Mean & \\
\hline $1965-2004$ & -77 & $-75,-21$ \\
$1975-2004$ & $-\mathbf{9 2}$ & $-\mathbf{9 7},-83$ \\
$1985-2004$ & -88 & $-\mathbf{9 5},-72$ \\
$1965-1975$ & 194 & $-7,843$ \\
$1975-1985$ & -34 & $-64,21$ \\
$1985-1995$ & -76 & $-86,-58$ \\
$1995-2004$ & -51 & $-78,6$ \\
\hline
\end{tabular}




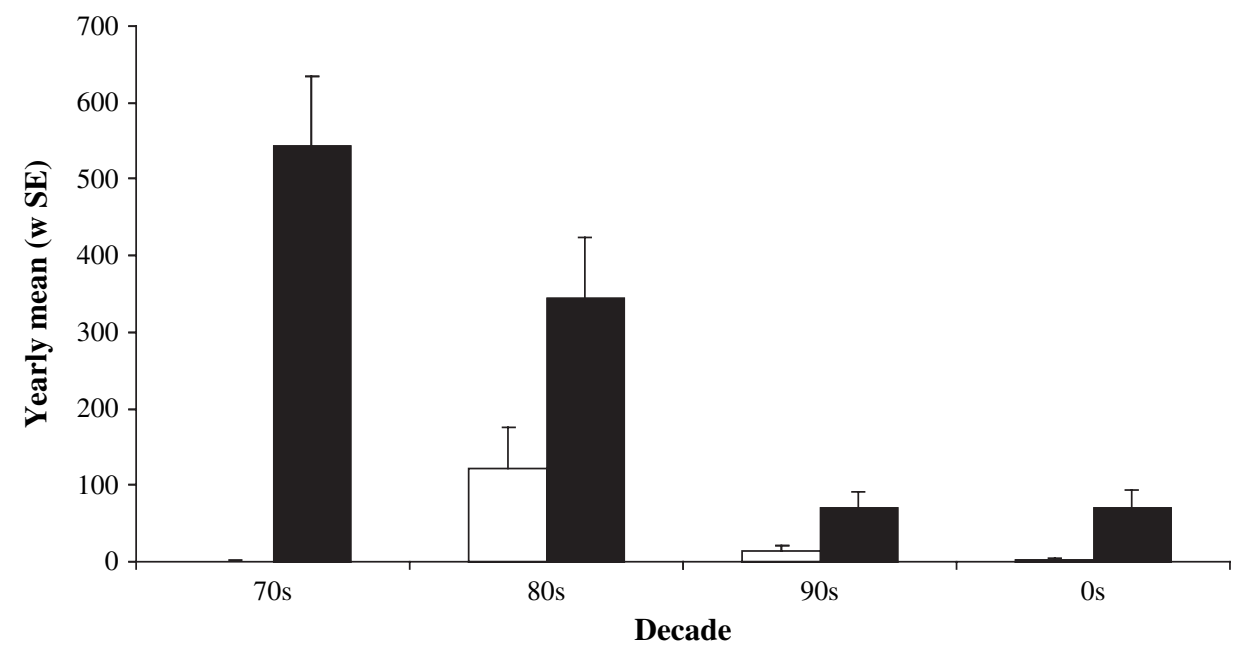

Figure 7. Mean $( \pm)$ number of Twite recorded, by decade, on passage at two coastal migration watch points; Black bars represent Gibraltar Point Bird Observatory (courtesy of Kev Wilson), White bars represent Landguard Bird Observatory (courtesy of Nigel Odin). Note, no data available for Landguard in the 1970s.

extensively on disturbed land containing a high density of favoured food plants (such as thistles Cirsium sp. and dandelions Taraxacum officinale) in their South Pennine breeding grounds (Raine 2006).

\section{Discussion}

In this paper, we have shown that it is possible to present a coherent picture of population change for a species, despite the initial disparity and wide range of data sources available. Understanding

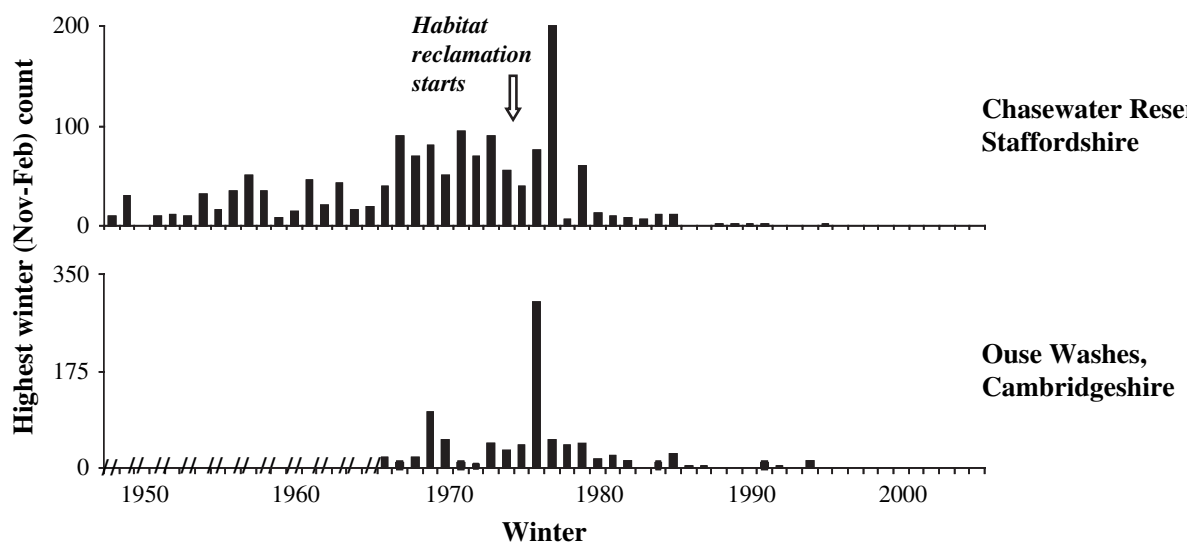

Figure 8. Maximum wintering Twite flock size at two inland wintering sites. (i) Chasewater Reservoir (SK0307), Staffordshire before and after habitat reclamation in 1974 (Source: Harrison and Harrison 2005; County Bird Reports). (ii) the Ouse Washes (TL4685), Cambridgeshire (Source: County Bird Reports). '//' symbols represent years where no data is available. 
population trends is, of course, vital in determining whether a species is in need of urgent conservation action, which in turn can be used to set conservation priorities. In the case of the Twite, we have shown that they have undergone a marked recent decline in both their breeding and wintering grounds in England. In the northern English uplands, where the species once bred regularly and was both widespread and numerous, Twite are now found only in a small part of the South Pennine Moors SPA. This decline appears to have commenced in earnest in the mid1950s, when the species disappeared first from lowland peatlands, due to a combination of peat extraction, drainage and land claim that altered the habitat to such an extent that these traditional breeding grounds could no longer sustain colonies (Oakes 1953, Newton 1972, Brown and Grice 2005) and then from much of its upland range.

Interestingly, data concerning wintering birds on the south and south-east coasts of England, and breeding birds on the two upland Common Bird Census plots and in the county of Staffordshire since 1967 suggest a modest peak in Twite numbers in the late 1960s and early 1970s. Indeed, after Staffordshire was re-colonised, Twite rapidly increased in numbers in that county (Lord and Munns 1970, Harrison et al. 1982). Notwithstanding the apparent buoyancy of Twite populations in the South Pennines, the species has now all but disappeared from much of the southern uplands, the northern Pennines, Cumbria, the Cheviots and the Borders (Newton 1972, Brown et al. 1995).

Our assessments of change are reflected in the observations of others. The first national survey of Twite was conducted in 1999 and led to an estimate of some 10,000 pairs in the UK, with a range lying between 6,000 and 15,000 pairs. This is substantially fewer than the only previous estimates made of 65,000 pairs for Britain and 3,000 for Ireland, derived using information on nesting densities obtained from a small number of locations and the numbers of 1o-kilometre squares found occupied by Twite during fieldwork for the 1988-1991 national breeding atlas. Though this earlier estimate is now thought to have been rather over-optimistic, there is corroborative evidence of decline from other sources (Langston et al. 2006, this paper). The range reduction between the $1968-72$ and $1988-91$ atlases was $1.1 \%$ for Britain and as much as $53 \%$ for Ireland (Gibbons et al. 1993) and the 1999 survey identified further losses, notably from Shetland, Orkney, Harris, Lewis, inland Scotland and from the South Pennines.

Furthermore, Carr and Middleton (2004) considered that the scale of the decline in the Peak District National Park since 1990 was greater than for any other upland species in this area and Skelcher (2002) failed to find any Twite during surveys of moorland fringe and in-bye land in the West Pennines, adjacent to the National Park. The 1999 survey of Twite in the South Pennines indicated a population of some 225 pairs, at the lower end of Brown et al's. (1990) estimate for the area of 200-400 pairs. Strict comparison using data only from areas of overlap indicated a decline of $56.9 \%$, from 415 to 179 pairs (Batty et al. 1999). Our failure to find Twite elsewhere in the Pennines, despite a considerable search effort both by ourselves and by many other fieldworkers, indicates strongly that the losses we have documented are not the result of a re-distribution of birds to new colonies.

Furthermore, numbers in the key wintering areas have also declined dramatically in recent decades. In the 1970s and 1980s, large numbers of Twite were reported from a significant number of traditional wintering grounds on the east and south-east coast of England. In the early 1970s there may have been as many as 20,000 to 60,000 Twite wintering along the Wash alone (Wilson 1974), with Davies (1988) estimating a population of 17,000 individuals in 1986 and flocks of 1,000 to 2,500 individuals recorded regularly (Lack 1986). These birds were then assumed to have come from the South Pennines, but this assumption is now well-supported by contemporary and more recent ring recoveries (Brown and Atkinson 2002, Raine et al. 2006).

Throughout the 1980s and 1990s, numbers at key wintering sites fell rapidly and flocks no longer wintered regularly in any inland areas. Numbers of wintering Twite recorded between 2003 and 2005 represent a fraction of the numbers recorded in the mid-1980s. For example, Holbeach Marsh in Lincolnshire held a flock of 5,000 individuals in 1972 and flocks of over 1,000 birds were recorded in several winters in the mid-1980s, yet held no wintering birds during our study (WeBS, County Bird Reports). Hamford Water in Essex showed a similar dramatic 
reduction, holding 2,000 birds in 1983 but only 45 in 2005 . In fact, every single site used for developing an index in this paper experienced dramatic crashes in wintering numbers in the $1980 \mathrm{os}$ to present, with the exception of Donna Nook in Lincolnshire. This site still retained a flock of between 100 and 300 individuals during the winters of 2003/04 to 2005/06, which is the same size as that held in 1970 (although there have been fluctuations in the intervening years). This is currently the largest coastal wintering flock known to the authors on either the east or south-east coast of England. While it is conceivable that the loss of wintering flocks may have been counteracted by a concomitant increase in birds wintering in the uplands (perhaps due to milder winters), research carried out by the authors of this paper has shown that while some wintering flocks now remain in the breeding grounds over-winter, these numbers are relatively small and concentrated around artificial feeding sites, and cannot account for the thousands of birds that are no longer present on the south-eastern coast of England in the winter (Raine 2006).

It is likely that the losses are related in some way to recent agricultural intensification in the uplands, the pace of which has increased dramatically in England in recent decades (Shrubb 2003). Indeed, the availability of breeding habitat was found to be the single most important variable in discriminating between historically-occupied sites with and without breeding Twite in the South Pennines (Raine 2006), implying that their loss from the historical colonies was associated with habitat loss. However, a marked decline in the extent and quality of coastal wintering sites, particularly those where pioneer salt marsh vegetation has been eroded as sealevels have risen, may also have had a significant impact on Twite populations (Atkinson 1998). Future population trajectories may well depend on whether upland breeding grounds are managed in ways that are sympathetic to the ecological requirements of this species and on whether coastal managed re-alignments can be engineered to produce the saltmarsh plants so favoured by Twite in winter.

We believe our example of Twite decline demonstrates that data from disparate sources can be used to present a coherent and quantitative account of population change. The approach might usefully be applied to a number of other species in the UK which are of conservation concern but for which we have a poorly refined quantitative record of change. Candidates might include other species of concern which are poorly represented in national monitoring schemes, such as the Water Rail Rallus aquaticus, Lesser Spotted Woodpecker Dendrocopos minor, Ring Ouzel Turdus torquatus, Grasshopper Warbler Locustella naevia, Marsh Tit Parus palustris, Willow Tit P. montanus and Bearded Tit Panurus biarmicus. In a wider European context, species that might benefit from this approach include Bonelli's Warbler Phylloscopus bonelli, Crested Tit Parus cristatus, Lesser Grey Shrike Lanius minor, Red-billed Chough Pyrrhocorax pyrrhocorax and Orotolan Bunting Emberiza hortulana. These species would benefit from similar efforts to draw together all available historical data to create a cohesive picture of population change, which would in turn serve to highlight and prioritise species for conservation action.

In an international context, the application of the approach is likely to be even more appropriate and applicable as in many countries conservation research is limited (either through funding or human resources). In these cases, the available data are even more likely to be widely dispersed and collected with varying conformity to standard recommended methods. Consideration might be given to recommending how the efforts of visiting ornithologists could be best tailored to complement those of resident ornithologists and how data collected through national recording schemes could more often permit the application of this approach.

\section{Acknowledgements}

We are very grateful to Aletta Bonn and the Moors for the Future Partnership, Dave Bingham, Nigel Odin (Landguard Bird Observatory), Kev Wilson (Gibraltar Point National Nature Reserve) and staff at Sandwich Bay Bird Observatory for sharing data. We would also like to thank Carole Showell at the British Trust for Ornithology library and Dr. Stephanie Prior 
(University of Cambridge) for help with some of the mapping work. We would like to thank the many birdwatchers in the South Penniner Study area who helped with the breeding surveys. They included Peter Grice, Nick Carter, David Sowter, Jim Hodgon and Brian Leecy. Special thanks to Helen Raine (BirdLife Malta) and Dr Simon Gillings (British Trust for Ornithology) for their helpful suggestions during the writing of this manuscript. This project was funded by English Nature and the Bermuda Government, and William Sutherland is supported by the Arcadia Fund.

\section{References}

Aebischer, N. J., Evans, A. D., Grice, P. V. and Vickery, J. A. (2000) Ecology and conservation of lowland farmland birds. Tring, UK: British Ornithologists Union.

Anon. (1999) Quality of life counts. Indicators for a strategy for sustainable development for the United Kingdom: a baseline assessment. London: Department of Environment, Transport and Regions.

Anon. (2002) Achieving a better quality of life. Review of progress towards sustainable development. London: Department of Environment, Transport and Regions.

Atkinson, P. A. (1998) The wintering ecology of the twite Carduelis flavirostris and the consequences of habitat loss. $\mathrm{PhD}$ thesis, University of East Anglia, UK.

Baillie, S. R., Marchant, J. H., Crick, H. Q. P., Noble, D. G., Balmer, D. E., Beaven, L. P., Coombes, R. H., Downie, I. S., Freeman, S. N., Joys, A. C., Leech, D. I., Raven, M. J., Robinson, R. A. and Thewlis, R. M. (2005) Breeding birds in the wider countryside: their conservation status 2004. Thetford, UK: British Trust for Ornithology. BTO Research Report 385.

Batty, A., Langston, R. H. W. and Gregory, R. D. (1999) South Pennines Twite survey 1999. Sandy, UK: Royal Society for the Protection of Birds.

BirdLife International (2004) Birds in Europe: population estimates, trends and conservation status. Cambridge, UK: BirdLife International. BirdLife Conservation Series No. 12 .

Brown, A. F. and Atkinson, P. A. (2002) Twite. Pp. 657-659 in: C. V. Wernham, M. P. Toms, J. H. Marchant, J. A. Clark, G. M. Siriwardena and S. R. Baillie, eds. The migration atlas: movements of the birds of Britain and Ireland. London: T. and A.D. Poyser.

Brown, A. F., Crick, H. Q. P. and Stillman, R. A. (1995) The distribution, numbers and breeding ecology of Twite Acanthis flavirostris in the South Pennines of England. Bird Study 42: 107-121.

Brown, A. F. and Grice, P. (2005) Birds in England. London: $\mathrm{T} \& \mathrm{AD}$ Poyser.

Carr, G. and Middleton, P. (2004) Breeding bird survey of the Peak District moorlands 2004. Bakewell, UK: Moors for the Future Partnership. Moors for the Future Report No. 1

Chamberlain, D. E. (2004) Lowland farmland birds: the road to recovery. A report on the BOUs Annual Conference held at the University of Leicester, 26-28 March 2004. Ibis 146: 704-706.

Davies, M. 1988. The importance of Britain's Twite. RSPB Conservation Review 2: 91-94.

Fewster, R. M., Buckland, S. T., Siriwardena, G. M., Baillie, S. R. and Wilson, J. D. (2000) Analysis of population trends for farmland birds using generalised additive models. Ecology 81: 1970-1984.

Fuller, R. J. and Gough, S. J. (1999) Changes in sheep numbers in Britain: implications for bird populations. Biol. Conserv. 91: 73-89.

Fuller, R. J., Gregory, R. D., Gibbons, D. W., Marchant, J. H., Wilson, J. D., Baillie, S. R. and Carter, N. (1995) Population declines and range contractions among lowland farmland birds in Britain. Conserv. Biol. 9: 1425-1441.

Fuller, R. J., Ward, E., Hird, D. and Brown, A. F. (2002) Declines in ground-nesting birds in two areas of upland farmland in the South Pennines of England. Bird Study 49: 146152. 
Gibbons, D. W., Reid, J. B. and Chapman, R. A. (1993) The new atlas of breeding birds in Britain and Ireland: 1988-1991. London: Poyser.

Gilbert, G., Gibbons, D. W. and Evans, J. (1998) Bird monitoring methods (a manual for techniques for key UK species). Sandy, UK: Royal Society for Protection of Birds.

Gregory, R. D., Wilkinson, N. I., Noble, D. G., Robinson, J. A., Brown, A. F., Hughes, J., Procter, D. A., Gibbons, D. W. and Galbraith, C. A. (2002) The population status of birds in the United Kingdom, Channel Islands and Isle of Man: an analysis of conservation concern 2002-2007. British Birds 95: 410-450.

Harrison, G. R., Dean, A. R., Richards, A. J. and Smallshire, D. (1982) The birds of the West Midlands. Worcester and London: Ebenezer Baylis and Sons Ltd.

Harrison, J. and Harrison, G. R. (2005) The new birds of the West Midlands. Worcester, UK: Goodman Baylis Ltd.

Jenkins, D. and Watson, A. (2001) Bird numbers in relation to grazing on a grouse moor from 1957-61 and 1988-98. Bird Study 48: 18-22.

Joys, A. C., Noble, D. G. and Baillie, S. R. (2003) Evaluation of species coverage and precision using the Breeding Bird Survey indexing method. Thetford, UK: British Trust for Ornithology. Research Report No. 317.

Lack, P. (1986) The atlas of breeding birds in Britain and Ireland. Calton, UK: Poyser.

Langston, R. H. W., Smith, T., Brown, A. F. and Gregory, R. D. (2006) The status of breeding twite Carduelis flavirostris in the UK. Bird Study 53: 55-63.

Lord, J. and Munns, D. J. (1970) Atlas of breeding birds of the West Midlands. Birmingham, UK: West Midlands Bird Club.

Marchant, J. H. (1983) Common Bird Census instructions. Tring, UK: British Trust for Ornithology.

Marchant, J. H., Hudson, R., Carter, S. P. and Whittington, P. (1990) Population trends in British breeding birds. Tring, UK: British Trust for Ornithology.

Newton, I. (1972) Finches. London: Collins.
Newton, I. (2004) The recent declines of farmland bird populations in Britain: an appraisal of causal factors and conservation actions. Ibis 146: 579-600.

Nuttall, J. (1968) Twite enquiry 1967 and 1968. Clitheroe, UK: East Lancashire Ornithologists' Club Report, East Lancashire Ornithologists' Club.

Oakes, C. (1953) Birds of Lancashire. Edinburgh and London: Oliver \& Boyd.

Ogilvie, M. and RBBP. (2003) Rare breeding birds in the United Kingdom in 2001. British Birds 96: 476-519.

Orford, M. (1973) Breeding distribution of the twite in central Britain. Bird Study 20: 51-62 and 121-126.

Raine, A. F. (2006) The breeding ecology of Twite Carduelis flavirostris and the effects of upland agricultural intensification. PhD thesis, University of East Anglia, UK.

Raine, A. F., Sowter, D. J., Brown, A. F. and Sutherland, W. J. (2006) Migration patterns of two populations of Twite Carduelis flavirostris in Britain. Ringing and Migration 23: 45-52.

R Development Core Team. (2006) R: A language and environment for statistical computing. R Foundation for Statistical Computing, Vienna, Austria. Available at http://www.r-project.org.

Robinson, R. A. and Sutherland, W. J. (2002) Post-war changes in arable farming and biodiversity in Great Britain. J. Appl. Ecol 39: $157-176$.

Shrubb, M. (2003) Birds, scythes and combines: a history of birds and agricultural change. Cambridge, UK: Cambridge University Press.

Siriwardena, G. M., Baillie, S. R., Buckland, S. T., Fewster, R. M., Marchant, J. H. and Wilson, J. D. (1998) Trends in the abundance of farmland birds: a quantitative comparison of smoothed Common Bird Census indices. J. Appl. Ecol. 35: 24-43.

Skelcher, G. (2002) Twite/moorland fringe birds/species rich grasslands. 2002 Twite survey report. Carnforth, UK: Lancashire County Council.

Vickery, J. A., Bradbury, R. B., Henderson, I. G., Eaton, M. A. and Grice, P. V. (2004) The 
role of agri-environment schemes and farm management practices in reversing the decline of farmland birds in England. Biol. Conserv. 119: 19-39.
Wilson, P. J. (1974) Wash wintering twite population study. Ecological report. Unpublished Report to Central Water Planning Unit, Reading, UK.

ANDRÉ F. RAINE*

BirdLife Malta, 57/28 Triq Abate Rigord, Ta'Xbiex XBX 1120, Malta.

ANDREW F. BROWN

Natural England, Northminster House, Peterborough PEI IUA, U.K.

TATSUYA AMANO

National Institute for Agro-Environmental Sciences, 3-1-3, Kannondai, Tsukuba-shi, Ibaraki, 305-8604, Japan.

WILLIAM J. SUTHERLAND

Department of Zoology, University of Cambridge, Cambridge CB2 3 EJ, U.K.

*Author for correspondence; e-mail: andre.raine@birdlifemalta.org

Received 13 October 2008; revision accepted 18 February 2009 